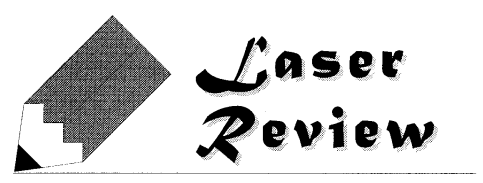

\author{
光周波数掃引コヒーレンストモグラフィ \\ 大林 康二 \\ 北里大学 一般教育部(兼)医療系研究科 (テ228-8555 神奈川県相模原市北里1-15-1)
}

Optical Coherence Tomography with Frequency Swept Sources

\author{
Kohji OHBAYASHI \\ Graduate School of Medical Science \& College of Liberal Arts and Sciences, Kitasato University, \\ 1-15-1 Kitasato, Sagamihara, Kanagawa 228-8555
}

(Received January 31, 2006)

\begin{abstract}
Recent developments of optical frequency domain imaging (OFDI) are reviewed. Two methods of OFDI using different types of frequency swept sources are compared.
\end{abstract}

Key Words: OCT (Optical Coherence Tomography), OFDR (Optical Frequency Domain Reflectometry), OFDI (Optical Frequency Domain Imaging), SSG-DBR (Super-Structured Grating Distributed-BraggReflector), Swept source

1.はじめに

OCT (Optical Coherence Tomography)は，無侵襲，非接触 に生体などの組織の断層像を，近赤外光を用いて測定す る装置で，1991年にMITのJ. Fujimoto等によって発表され て以来 ${ }^{1)}$, 医用画像診断の重要な方法であることが実証さ れるとともに工業的応用への可能性も示されつつある21. OCTの方法に着目すると, これまでに臨床や生物学の応 用に適用された方法はすべて最初に開発された時間領域 (Time-Domain: TD) OCTである，OCTの応用範囲を広げる ためには，この方法には限界があることが指摘されてき ている．たとえば，臨床的な生体組織のスクリーニング の診断では，患部を見落とさないためにできるだけ広い 診断部位の高速の3次元的断層像の測定が求められるが, 高速になるほどOCTの感度は減少する，TD-OCTでは，奥 行き方向測定の繰り返し周波数 (A走査率) が数 $\mathrm{kHz}$ 以上に なると, 感度が生体組織を必要な侵達度を確保して測定 するための限界である約 $105 \mathrm{~dB}$ 程度よりも悪くなってしま い,これ以上速い速度の測定は無理であると考えられて いる.

これに対し，フーリエ領域(Fourier-Domain:FD)OCTは, TD-OCTに比べて $20 \mathrm{~dB} \sim 30 \mathrm{~dB}$ 程感度が良いために3,4)，同 じ測定の感度ならTD-OCTよりも100～1000倍高速に走査 できる. このため, 最近FD-OCTの研究が盛んになって来 ている. FD-OCTには, 分光器を用いるスペクトル領域 (Spectral Domain: SD) OCTと光源の周波数を掃引する光周 波数掃引 (Optical Frequency Domain Reflectometry: OFDR) OCTとの2つの方法がある。OFDR-OCTは，最近はOFDI
(Optical Frequency Domain Imaging) と呼ばれることが多く なって来ている. また, 周波数を掃引する光源 (swept source: SS) を用いるので, SS-OCTとも呼ばれている。こ こでは以降OFDIと呼ぶことにする。

SD-OCTでは，TD-OCTと同じスペクトル幅の広い広帯 域光源を用いるが, 干渉信号を分光器で分光しCCDで検 出する.SD-OCTの研究は最近目覚しく発展し, 従来の TD-OCTよりも一桁程速い高速測定に成功した。しかし, 検出に用いる分光器の分解能で計測可能距離が短く制限さ れたり，血管の内壁を測定するプローブを高速で回転する と断層像の一部が失われる “位相消滅”と呼ばれる問題など が指摘されている。これに対し，同じFD-OCTでもOFDIに はそのような欠点はなく, SD-OCTよりも優れた方法とし て期待が寄せられている。本稿の締め切り間際の2006年1 月末に, OCTの研究が活発に報告されるSPIE, Photonics Westが開かれたが，SD-OCTが中心の昨年とは様変わり し, OFDIの報告が沢山され, 最近のOFDIの進展が話題を さらっていた，本稿ではOFDIの最近の発展について紹介 する。

\section{2. 光周波数掃引OCTの原理}

光周波数掃引コヒーレンストモグラフィ(OFDI)の基本 となる,リフレクトメトリーであるOFDRの基本構成を Fig. 1に示す. 光ファイバ光学系でマイケルソン干渉計を 構成する. 光源には光周波数掃引光源 $(\mathrm{SS})$ を用い, 出力 光をカプラ $(\mathrm{C})$ で分割し，一方を参照光路 $(\mathrm{RA})$ に他方を試 料光路 $(\mathrm{SA})$ に導入する。参照光路には固定された反射ミ 


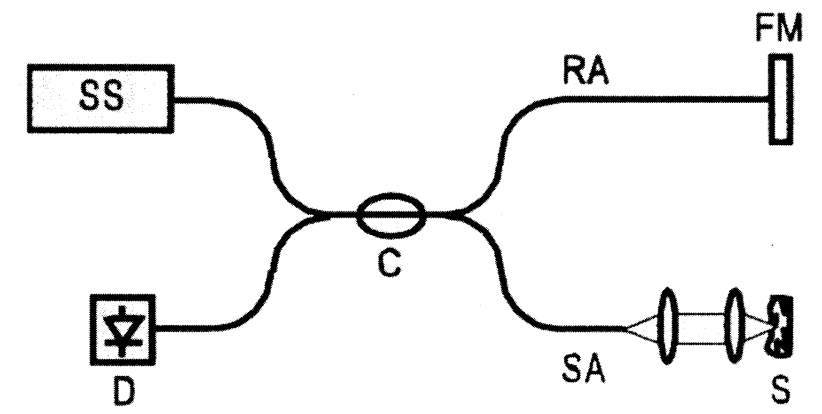

Fig. 1 Basic configuration of the optical frequency domain reflectometry (OFDR).

ラー $(\mathrm{FM})$ があり, 反射光は参照光路を経由してカプラに 杘る. 試料光路を経由して試料 $(\mathrm{S})$ に照射され, 試料内部 から反射(後方散乱も含む) された光は, 試料光路を経由し てカプラに戻る．参照光路と試料光路からカプラに戻っ た光は, カプラで干渉し, この干渉光を, 通常の光検出 器(D)で検出する.

カプラからの参照光路と試料の内部の任意の点との光 路差を $z$ とると, その点から反射された光の干渉信号 $P_{i}$ (z) は次式で与えられる.

$$
P_{i}=2 \sqrt{r(z) I_{0} I_{r}} \cos \left(2 k_{i} z\right)
$$

ここで, 添え字 $i$ は光周波数掃引の起点から数えて $i$ 番目を 示し, $r(z)$ は光路差 $z$ における試料の後方反射率, $I_{0}$ は試料 に照射された光の強度， $I_{r}$ は参照光の強度， $k_{i}$ は $i$ 番目の光 の波数である. 光の波数 $k$, 波長 $\lambda$, 周波数 $f$ との間には, $k=2 \pi / \lambda=2 \lambda f / c$ の関係があり, 光周波数を掃引することは 波長や周波数を掃引することにもなる.Fig. 1の構成で は, 検出器には干渉信号の他に直流成分の光 $I_{r}$ も射する が，後に示すようにこれを取り除く光学系の構成が可能 である。実際の検出器には, 式(1)を $z$ のべての值につい て積分した光が入射するが，説明を簡単にするため任意 の点との光路差zからの信号に着目する.

$z$ の点からの信号を他の信号と区別して検出するために はフーリエ変換を用いる. 光周波数を掃引して波数を $k_{1}$, $k_{2}, \ldots, k_{N}$ と等間隔 $\lambda k$ で掃引する場合, 式 (1)にそれぞれ $\cos \left(2 k_{i} Z\right)$ と $\sin \left(2 k_{i} Z\right)$ を乗じて $k_{i}$ についての和をとって得ら れる量の二乗和を求めると, 次式となる5).

$$
P_{s}^{2}(Z, z)=4 r(z) I_{0} I_{r}\left\{\frac{\sin [N \delta k(Z \mp z)]}{\sin [\delta k(Z \mp z)]}\right\}^{2}
$$

この式は， $Z= \pm z て ゙$ 鋭いピークを示すが，Zの正負は区別 できないので, 重なって(縮退して)検出される，通常，ど ちらかの側のみを測定するように試料を配置する．信号 は全てのzからの寄与が重なって検出されていると説明し たが, 式(2)に示すように, フーリ工変換に用いるZの值 によって，試料の位置 $z=Z$ における反射率 $r(Z)$ が，重な り積分された信号の中から抽出できることになる，Zを試 料の全奥行き方向の位置すべてに亘って変化させてフー リ工変換を行えば, 奥行き方向の位置の関数として反射 率が求められる。このような測定をA走査と呼ぶ.

式(2)より，試料を

$$
\Delta z=\frac{\pi}{2 \delta k}
$$

以内に設定しないと, 折り返され重なって検出される部 分が生じるので，式(3)で与えられる $\Delta z$ が測定可能距離に なる. 式(2)のピークの半值全幅 (FWHM) $\delta z$ は次式とな り, これがOFDIの奥行き方向の分解能になる.

$$
\delta z=\frac{2.78}{N \delta k}
$$

この式で分解能があたえられるのは，出力スペクトル波 形が矩形の場合で, 中心波長が $\lambda_{c}$, 半值全幅が $\Delta \lambda$ のガウ ス的なスペクトル波形の場合は，分解能 $\delta z$ z以下の式にな る.

$$
\delta z=\frac{2 \ln 2}{\pi} \frac{\lambda_{c}^{2}}{\Delta \lambda}
$$

\section{3. 光周波数掃引OCTの方法}

上述したように，OFDRでは一度の光周波数掃引でA走 査を行えるが，高速の測定を行うためには，周波数を高 速で掃引しなければならない。単位時間当たりのA走査の 数を $\mathrm{A}$ 走查率と呼ぶ. OFDIの測定可能距離 $\Delta z$ z長くする ためには，式(3)より掃引する波数のステップ幅 $\delta k を$ 細か くしなければならない. その上で分解能 $\delta z$ を怔るために

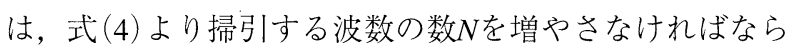
ない.

高いA走査率の高速測定を行うためには，周波数の掃引 速度を上げなければならない。このような光源の実現は 難しかったため，原理的には優れていることが期待され ていたが，医療診断に用いることができる性能のOFDIは なかなか実現しなかった. しかし，ごく最近2種類のレー ザーで実現可能となった。

1つはSSG-DBR (Super-Structured Grating DistributedBragg-Reflector) レーザーで，もう一つはECDL (ExtendedCavity Diode Laser)である.この2つは，Fig. 2に示すよう に，光周波数fの掃引の仕方で大きく異なる. SSD-DBR レーザーはFig. 2 (b) に示すように階段的であるが, ECDL はFig. 2 (a) に示すように連続的である.

ECDLの構成の一例をFig. 3 に示す6). 光ファイバのリン グ状の光路に, 光増幅用のSOA (Semiconductor Optical Amplifier)を入れる. 光路に光サーキュレータを用い, 回 折格子とポリゴンミラーで構成される波長フィルターを

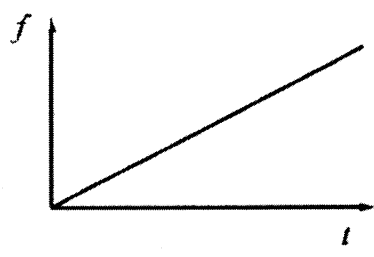

(a)

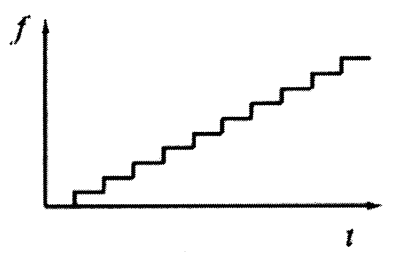

(b)
Fig. 2 Two methods of frequency sweeping for optical frequency domain imaging (OFDI). (a) continuous sweeping, (b) step-like sweeping. 
入れる。この波長フィルターで選択される波長でレー ザー発振が起きる。この波長は，ポリゴンミラーの回転 によって掃引できる。ポリゴンミラーは高速で回転でき るため, 高速の光周波数掃引が可能となる.

これと類似の光源がSantec社で開発された.この光源を 用いて行なわれたYasuno等のOFDIの結果を紹介する ${ }^{8)}$. 光源の中心波長 $1310 \mathrm{~nm}$, スペクトル幅は $110 \mathrm{~nm}, \mathrm{~A}$ 走査 率は $20 \mathrm{kHz}$ であった。 OCTの感度は $-112 \mathrm{~dB}$, 分解能は空 気中で $6.9 \mu \mathrm{m}$ が実現できた。前述の離散的なフーリエ変換 は，等間隔の波数に対して行なう. 連続的な周波数掃引 光源の場合は, 干渉信号のサンプリングは波数領域で等 間隔では行なわれない. Fig. 3の光源の場合, 波長領域で ほぼ等間隔のサンプリングが行なわれている。これを， 等間隔の波数のデー夕に変換するためにリスケーリング の処理が行なわれるが，このOFDIは安定していて，一度 校正を行なうと, 数ヶ月に亘って同じ校正值を用いるこ とができる点が優れている.

もう一つの連続的な周波数掃引レーザーの例では, 波 長選択を同調可能なFabry-Perotフィルターで行う ${ }^{9)}$. 連続 的に周波数掃引を行なう光源の場合, 掃引の速度を上げ ると干渉距離が短くなり，このため観測可能距離が式 (3) で与えられる距離よりも短くなるという久点があっ た7-9). Hubar等はこの点を改良して, 干渉距離の長い, 高 速で周波数掃引できる光源を開発した ${ }^{10)}$.

Hubar等の開発した周波数掃引光源の構成をFig. 4に示 す. $7 \mathrm{~km}$ の分散制御ファイバをファイバリングキャビ ティー内に挿入したことが特徵である。リングキャビ ティー長は約 $10 \mathrm{~km}$ で, 光が一周するのにかかる時間の逆 数にあたる周波数は約 $30 \mathrm{kHz}$ である。実測では, FabryPerotに入力する変調信号が，29，58，116，145 kHzのと きに共鳴的なレーザー発振が観測された。正弦波の変調 信号の増減の両側をOCTの1つのA走査に用いることがで きるので，A走査率は，58，116，232，290 kHzが可能で ある。

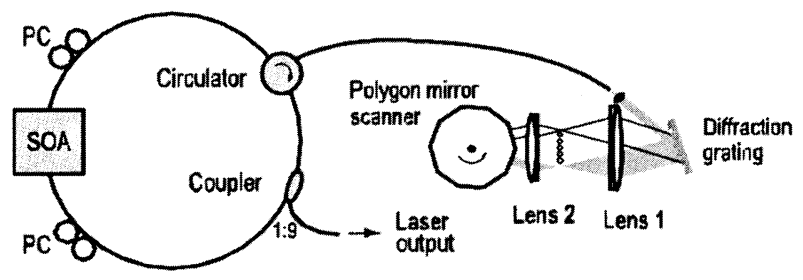

Fig. 3 An example of the extended cavity diode laser.

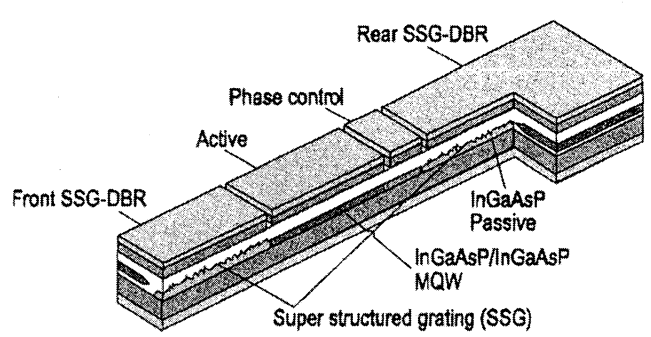

(a)

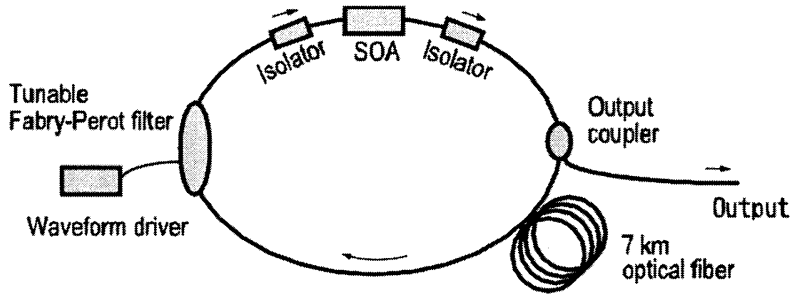

Fig. 4 Configuration of the extended cavity diode laser demonstrated ultra-high repetition rate and long coherence length.

このレーザーの特徵は; 発振がS O A からのA S E (amplified spontaneous emission) を種にするのではなく, キャビティーを一周して戻ってきたレーザー光に同期し てそれを種にするので，干渉距離が長い点にある．瞬間 のスペクトル幅は $0.01 \mathrm{~nm}$ 以下であって, OCT信号の奥行 き $10 \mathrm{~mm}$ での強度の低下は約 $6 \mathrm{~dB}$ 以下である。 OCTと しての他の性能は, 中心波長 $1300 \mathrm{~nm}$, スペクトル幅 145 $\mathrm{nm}$ で生体組織内の分解能約 $6.2 \mu \mathrm{m}$, 出力約 $35 \mathrm{~mW}$ であ る. $58 \mathrm{kHz}$ のA走査率での人の皮膚のOCT信号が報告され ている10).

Fig. 4に示すHuber等の開発した光源は, 光周波数掃引 OCTに求められる殆ど全ての要請を満たしている，今後 は，このレーザーに限らず，さらに発展させた考え方も 取り入れて, 類似の多くの連続的な光周波数掃引OCTが 開発されるだろう。

これまで開発された連続的な光周波数掃引OCTの残さ れた問題は, 光周波数 (波数)掃引の時間に対する非線形性 である。干渉信号は等時間間隔でサンプリングされる が，高速フーリエ変換を行なうためには，サンプリング されたデータを周波数で等間隔になるようにその都度り スケーリングしなければならない.

周波数 (波数)で等間隔の干渉信号のサンプリングを可 能にするのが，筆者らが開発した，SSG-DBRレーザーを 光源に用いたOFDIである．SSG-DBRレーザーの概略図を Fig. 5 (a)に示す.

このレーザーの動作原理の詳細は, 文献を参照された い11,12). OCTへの応用の面から特徵を述べると, Fig. 2 (b) に示すように等間隔の階段状で周波数掃引ができるため リスケーリングが不要, 出力強度分布は一定になるよう に制御でき，周波数の階段状変化のスイッチ時間は数ナ ノ秒で高速の掃引が可能, レーザー素子自体の長さは数 $\mathrm{mm}$ 以下で電源を加えても極めて小型にできるなどであ

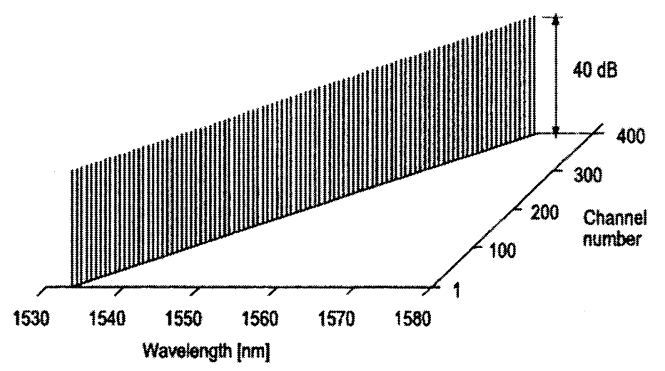

(b)

Fig. 5 (a) The structure of the SSG-DBR laser. (b) The emission spectrum of the SSG-DBR laser. 


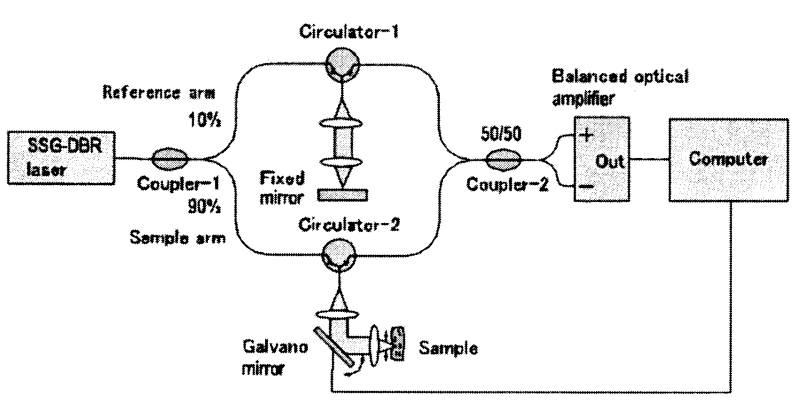

Fig. 6 Configuration of optical frequency domain imaging (OFDI) system.

る.

SSG-DBRレーザーはNTTフォトニクス研究所で光通信 用に試作開発された。この試作レーザーを光源に用いた OCT計測の例を紹介する ${ }^{5,13,14)}$. OFDIの概略の装置構成を Fig. 6に示す. 干渉計は, 参照光路 (Reference arm) と試料 光路 (Sample arm) を別としたマッハツェンダー型で構成し ている。この図では参照光路には，試料光路の光路長を 空気中で補償するための光学系を用いている．参照文献 では分散は数值補正することにして，この光学系は省略 したが，Fig.6の構成の方が計算処理が簡単である。試料 に照射する光は，ガルバノミラー(Galvano mirror)で試料 (Sample)上を走査できるようにしてある。参照光路と試 料光路の光をカプラー (Coupler-2) で受光して差動の光検 出増幅器 (Balanced optical amplifier) で検出すると, 光の直 流成分は差し引きキャンセルされて，式(1)で示す干渉信 号のみが増幅器から出力される。

試料への測定光の照射方向をGalvano mirrorを用いて光 軸に対し横方向に走査しながら次々とA走査を繰返し，そ れぞれをフーリエ変換して得られた反射強度を，奥行き 方向と横方向の平面上にグレースケールまたはそれをカ ラーコードに変換してカラーマップとして描けば，OFDI による断層像が得られる。

このようにして得られたSSG-DBRレーザーを光源に用 いたOFDI断層像の例をFig. 7に示す ${ }^{13,14)}$. Fig. 7 (a) は摘 出した豚の眼の前眼部で，角膜 (Cornea), 虹彩 (Iris), 前 房(Anterior chamber) などが良く見えている. Fig.7 (b) は 人の皮膚で，表皮と真皮が分離でき，指紋が良く見えて いる．筆者らの研究以前は，OFDIの光源は連続的に周波 数を掃引しなければならないとされていた15)。現在でも そのように記述する文献を散見する。階段的周波数掃引 光源を用いてOFDIを実証したのは筆者らが初めてであ る.

この通信用に試作されたSSG-DBRレーザーを光源とす るOCTの主な性能は，波長範囲はFig. 5 (b)に示すように 1533.17 から $1574.13 \mathrm{~nm}$ で式(4)より空気中の分解能は26 $\mu \mathrm{m}$ であり，周波数間隔は $12.5 \mathrm{GHz}$ (波長間隔は約 $0.1 \mathrm{~nm}$ ) で式(3)より測定可能距離は $6 \mathrm{~mm}$ であり，階段状変化の時 間間隔は $10 \mu \mathrm{s}$ でA走査率 $250 \mathrm{~Hz}$ である。これらの性能は, 前述した連続的周波数掃引光源を用いたOCTに比べて 劣っている。

筆者等は，現在NTTフォトニクス研究所と共同でSSG-

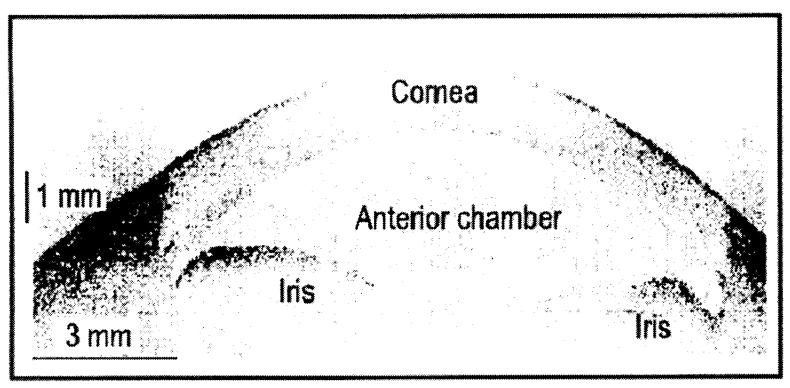

(a)

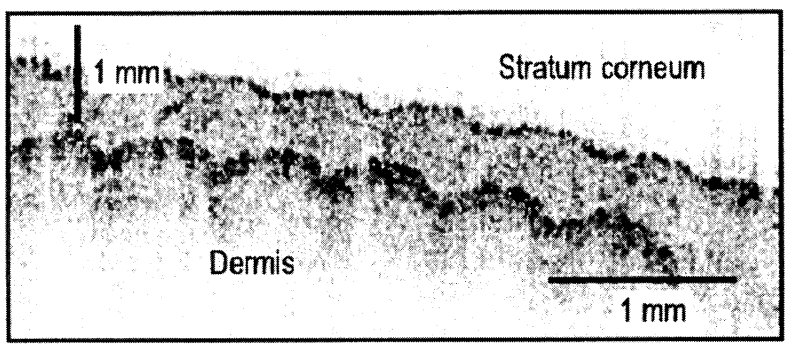

(b)

Fig. 7 Examples of OCT images observed with optical frequency domain imaging (OFDI) using an SSG-DBR laser.

DBRレーザーを光源とする新しいOCTの開発を進めてい る. 光源の目標仕様は，中心波長 $1530 \mathrm{~nm}$ ，掃引波長範囲 $1450 \mathrm{~nm}$ から $1610 \mathrm{~nm}$ まで，掃引波長幅 $160 \mathrm{~nm}$ ，階段的周

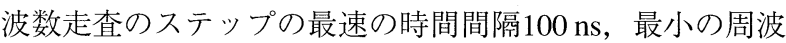
数間隔 $6.25 \mathrm{GHz}$ である。この光源と, 階段的な周波数走 査の利点を生かした干渉計の構成により，OFDIの性能と して, 深さ方向の分解能 $6.5 \mu \mathrm{m}$ (屈折率1.380物質中で 4.7 $\mu \mathrm{m})$, 最速 $\mathrm{A}$ 走査率 $75 \mathrm{kHz}$ ，最長計測可能距離 $12 \mathrm{~mm}$ 実現する予定である。

謝 辞

この報告に関連した著者の研究は, 北里大学一般教育 部物理学研究室, 北里大学大医学部眼科学清水研究室, NTTフォトニクス研究所フォトニクスデバイス研究部のス タッフの協力を得て進められている。また，この研究は (独) 科学技術振興機構 (JST)の「先端計測分析技術・機器 開発事業」の援助を受けている.

\section{参考文献}

1) D. Huang, E. A. Swanson, C. P. Lin, J. S. Schuman, W. G. Stinson, W. Chang, M. R. Hee, T. Flotte, K. Gregory, C. A. Puliafito, and J. G. Fujimoto: Science 254 (1991) 1178.

2) C. Mason, J. F. Markusen, M. A. Town, P. Dunnill, and R. K. Wang: Phys. Mod. Biol. 49 (2004) 1097.

3) M. A. Choma, M. V. Sarunic, C. Yang, and J. Izatt: Opt. Exp. 11 (2003) 2183.

4) R. Leitgeb, C. K. Hitzenberger, and A. F. Fercher: Opt. Exp. 11 (2003) 889

5) T. Amano, H. Hiro-Oka, D. H. Choi, H. Furukawa, F. Kano, M. Takeda, M. Nakanishi, K. Shimizu, and K. Ohbayashi: Appl. Opt. 44 (2005) 808. 
6) S. H. Yun, C. Boudoux, G. J. Tearney, and B. E. Bouma: Opt. Lett. 28 (2003) 1981.

7) S. H. Yun, G. J. Tearney, B. E. Bouma, B. H. Park, and J. F. de Boer: Opt. Exp. 11 (2003) 3598.

8) Y. Yasuno, V. D. Madjarova, S. Makita, M. Akiba, A. Morosawa, C. C. Chong, T. Sakai, K. P. Chan, M. Itoh, and T. Yatagai: Opt. Express 13 (2005) 10652.

9) R. Huber, M. Wojtkowski, K. Taira, and J. G. Fujimoto: Opt. Exp. 13 (2005) 3513

10) R. Huber, K. Taira, M. Wojtkowski, and J. G. Fujimoto: Proc. SPIE 5861 (2005) 58611B.

11) Y. Tohmori, Y. Yoshikuni, H. Ishii, F. Kano, T. Tamamura, Y. Kondo, and M. Yamamoto: IEEE J. Quantum Electron. 29 (1993)
1817.

12) H. Ishii, H. Tanobe, F. Kano, Y. Tohmori, Y. Kondo, and Y. Yoshikuni: IEEE J. Quantum Electron. 32 (1996) 433.

13) T. Amano, H. Hiro-Oka, D. H. Choi, H. Furukawa, F. Kano, M. Takeda, M. Nakanishi, K. Shimizu, and K. Ohabayshi: Proc. SPIE 5531 (2004) 375.

14) D. Choi, T. Amano, H. Hiro-Oka, H. Furukawa, T. Miyazawa, R. Yoshimura, M. Nakanishi, K. Shimizu, and K. Ohbayashi: Proc. SPIE 5690 (2005) 101.

15) C. K. Hitzenberger and A. F. Fercher: in Handbook of Optical Coherence Tomography, B. E. Bouma and G. J. Tearney, eds. (Marcel Dekker, New York, 2002) p. 359.

\section{レーザーワード}

光周波数領域画像法 (OFDI)

近赤外線光源を用いたマイケルソン干渉計やマッハ ツェンダー干渉計を利用して, 生体などの断層画像を撮 像するオプティカル・コヒーレンス・トモグラフィ (OCT)の方法の一つ. Optical Frequency Domain Imagingの 略.この方法は, OFDR-OCT (Optical Frequency Domain Reflectometry-Optical Coherence Tomography) とも呼ばれ る. 従来のOCTでは, 広帯域光源を用い, 干渉計の一つ
のアームの長さを変えて計測していたが，OFDIでは， アームの長さは固定したままで, 瞬間的なスペクトル幅 は狭い光源の光の周波数を, 幅広い周波数領域上で掃引 して，それぞれの周波数で干渉信号を測定し，これら干 渉信号の集合に対して離散的なフーリエ変換を行ない, OCT断層画像を撮像する。高速で高感度の計測ができる ので, OCTの手法の主流となりつつある。（大林 康二） 